\title{
Desain Pintu Air Berbantu Komputer untuk Saluran Irigasi Tersier
}

\author{
(Computer Aided Design for Sluiced Gate in Tertiary Irrigation Canal)
}

\author{
Kukuh Aldi Sanyoto ${ }^{1 *}$ dan Budi Indra Setiawan ${ }^{1}$ \\ ${ }^{1}$ Departemen Teknik Sipil dan Lingkungan, Fakultas Teknologi Pertanian, Institut Pertanian Bogor. \\ J1. Raya Dramaga, Kampus IPB Dramaga, PO BOX 220, Bogor, Jawa Barat, Indonesia \\ * Penulis Korespondensi: kukuhaldiez@gmail.com
}

Diterima: 29 Juni 2020

Disetujui: 22 September 2020

\begin{abstract}
The effort of human creativity in the field of hydraulics in overcoming the problem of irrigation, one of which is using floodgates. The discharge from the floodgates needs to be adjusted to the water needs of the plant. However, due to the long design process, the computer aided design of sluice on tertiary irrigation channels is needed in order to be able to set the optimum dimensions and output discharges of crops water needs with fast design time. The tool used in the form of a computer device with Ms Excel and AutoCAD software and materials used were secondary data, that is water needs of local varieties of rice plants in Mangkung, Rambitan, NTB on an area of 50 ha. The data's then calculated and the largest discharge is $0.12 \mathrm{~m}^{3} / \mathrm{s}$ with plant evapotranspiration of $5.10 \mathrm{~mm} /$ day and $6.43 \mathrm{~mm} /$ day of effective rainfall, meanwhile the smallest is $0.02 \mathrm{~m}^{3} / \mathrm{s}$ with plant evapotranspiration of $3.17 \mathrm{~mm} /$ day and $3.47 \mathrm{~mm} /$ day of effective rainfall. The dimensions of the steel sluice gates obtained are width of sluice gate $0.40 \mathrm{~m}$, height of sluice gate is $0.80 \mathrm{~m}$ with an estimated cost of making Rp 7,547,000 per one sluice. The dimensions of the GFRP sliding sluice gates are width of sluice gate $0.50 \mathrm{~m}$, height of sluice gate is $0.75 \mathrm{~m}$ with an estimated construction cost of $R p$ 7,547,000 per one sluice.
\end{abstract}

Keywords: crops water needs, dimension, discharge, optimum, sluice

\section{PENDAHULUAN}

Sumberdaya air menjadi salah satu faktor kebutuhan utama dalam pertanian. Namun, akibat beberapa faktor menyebabkan sumberdaya air untuk pertanian menjadi terbatas. Salah satu faktor tersebut adalah penggunaan air yang berlebih atau tidak efisien dalam pengairan sehingga menyebabkan ketersediaan air menjadi berkurang. Pada saat ini ketersediaan air merupakan faktor yang sangat mempengaruhi kebutuhan air di sawah. Air yang tidak cukup menyebabkan pertumbuhan padi tidak sempurna bahkan bisa menyebabkan padi mati kekeringan (Rizal et al., 2014).
Usaha daya cipta manusia dalam bidang hidrolika dalam mengatasi masalah pengairan khususnya pada bangunan-bangunan seperti bangunan pintu air, waduk, saluran, bendung dan lain sebagainya telah sering dilakukan namun bentuk penyelesaian tersebut sifatnya dapat beragam untuk setiap orang, tergantung obyek yang ditinjau, salah satunya yaitu debit. Mengetahui debit aliran dalam akan sangat penting untuk dapat mengontrol laju penggunaan air sesuai dengan kebutuhan. Nilai debit dapat diketahui dengan melihat besarnya kebutuhan air pada tanaman, sehingga diharapkan akan dapat mengontrol debit aliran sesuai dengan yang dibutuhkan tanaman. Oleh karena itu diperlukan 
pintu air yang merupakan salah satu alat atau komponen penunjang kegiatan dalam manajemen pengaturan aliran air (Laumal et al., 2017).

Perancangan (desain) pintu air masih banyak menggunakan metode konvensional dimana baik dalam perhitungan dan penentuan dimensi masih dilakuakan secara manual. Kondisi tersebut sangat kurang efisien terkait time consuming pada saat desain. Oleh karena itu, perlu dikembangkan desain berbantu komputer untuk mengotomasi proses desain, dengan harapan akan dapat mengurangi time consuming pada saat proses desain (Rif'ah \& Wibisono, 2016). Desain berbantu komputer memiliki keunggulan yaitu hasil dari model geometrik produk yang telah dibuat dapat dimanipulasi, dianalisa, dan diperhalus untuk kondisi yang berubah-ubah (Ningsih, 2005). Kondisi ini dapat membantu mempermudah dan mempercepat apabila dilakukan perancangan ulang pintu air kembali. Salah satu cara dalam desain berbasis komputer dapat dilakukan dengan menggunakan fitur dalam aplikasi MS Excel yaitu Microsoft Visual Basic.

Penelitian yang dilakukan bertujun untuk mengetahui debit kebutuhan air tanaman yang dipengaruhi oleh evapotranspirasi tanaman dan curah hujan efektif yang terjadi, meningkatkan efektivitas penggunaan pintu air untuk mengatur debit air pada petak tersier sehingga mengurangi kelebihan air dalam memenuhi kebutuhan air tanaman, menghasilkan rancangan pintu air untuk saluran irigasi tersier yang optimum dengan bantuan komputerisasi, dan memperoleh rencana anggaran biaya (RAB) hasil rancangan pintu air.

\section{METODOLOGI}

Penelitian dilaksanakan pada bulan April 2020 sampai Mei 2020. Pengumpulan bahan penelitian dengan mengumpulkan data dari peraturan yang berlaku dan literatur dengan kasus yang sejenis. Analisis data akan dilakukan di Departemen Teknik Sipil dan Lingkungan, Institut Pertanian Bogor.

Perlengkapan yang digunakan dalam penelitian ini adalah seperangkat komputer (hardware) yang dilengkapi dengan software MS Excel dan Microsoft Visual Basic yang digunakan untuk melakukan perhitungan. Selain itu, digunakan juga AutoCAD untuk pemodelan gambar pintu air 2D dan 3D. Bahan yang digunakan dalam penelitian berupa data sekunder yaitu data kebutuhan air tanaman dan kriteria umum untuk petak tersier berdasarkan Standar Perencanaan Irigasi KP-05 (KemenPU, 2013), kriteria umum perancangan pintu air berdasarkan Standar Perencanaan Irigasi KP-08 (KemenPU, 2013), dan hasil studi kasus sejenis.

Penelitian diawali dengan dengan ide penelitian yang dikembangkan menjadi perumusan masalah. Kemudian dilanjutkan dengan studi literatur terkait topik dan masalah yang diambil. Selanjutnya dilakukan pengumpulan data pengolahan dan analisis data. Pengumpulan berbagai macam literatur seperti buku, jurnal, skripsi, dan standar peraturan yang berlaku serta karya tulis ilmiah lainnya yang sesuai dengan topik penelitian. Data yang dikumpulkan berupa data sekunder meliputi jenis tanaman, umur tanaman, jenis tanah, evapotranspirasi potensial $\left(\mathrm{ET}_{0}\right)$, dan curah hujan efektif (Re). Data yang dikumpulkan akan menjadi acuan untuk mendapatkan data koefisien tanaman (Kc), penjenuhan tanah (SAT), pelapisan air (WL) dan perkolasi (PERC). Selain 
itu, dipelukan juga data luas petak pertanian yang diairi serta jenis pintu sorong sesuai standar yang berlaku.
Prosedur penelitian dapat dilihat pada Gambar 1.

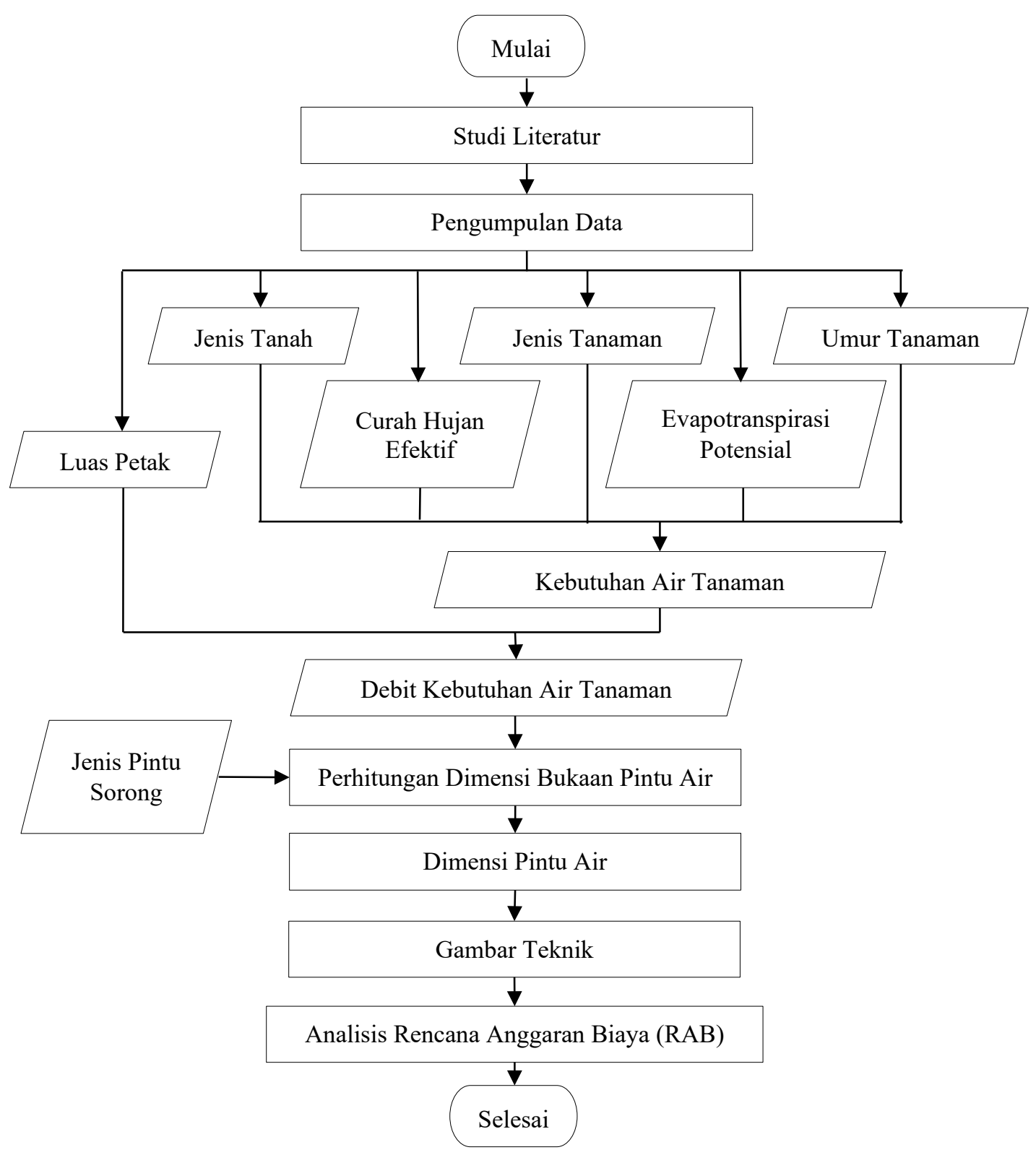

Gambar 1 Diagram Alir Prosedur Penelitian

Data sekunder yang dikumpulkan kemudian dimasukkan ke dalam spreadsheet di MS Excel untuk dilakukan perhitungan evapotranspirasi tanaman, kebutuhan air irigasi, kebutuhan pengambilan air, dan debit 
kebutuhan air tanaman pada Persamaan (1), Persamaan (2), Persamaan (3), dan Persamaan (4).

ETcrop $=E T_{0} \times K c$

Keterangan:

ET crop = evapotranpirasi tanaman (mm/hari)

$\mathrm{ET}_{0}=$ evapotranpirasi potensial untuk tanaman (mm/hari)

Kc $=$ koefisien tanaman

$I N=E T c r o p+S A T+P E R C+W L-R e$

Keterangan:

IN = air irigasi yang dibutuhkan (mm/hari)

SAT $=$ penjenuhan $(\mathrm{mm} / \mathrm{hari})$

$\mathrm{WL}=$ water layer $(\mathrm{mm} / \mathrm{hari})$

Re $\quad=$ curah hujan efektif (mm/hari)

PERC = perkolasi $(\mathrm{mm} / \mathrm{hari})$

$D R=\frac{I N}{8,64 \times e}$

Keterangan:

DR = kebutuhan air (lt $/ \mathrm{dt} / \mathrm{ha})$

e $\quad=$ efisiensi irigasi (petak tersier $=65 \%$ )

$1 / 8,64=$ angka konversi satuan dari $\mathrm{mm} / \mathrm{hari} \mathrm{ke} \mathrm{lt/dt/ha}$

$Q=D R \times A$

Keterangan:

Q = debit kebutuhan air tanaman
$\mathrm{A} \quad \begin{aligned} & \left(\mathrm{m}^{3} / \mathrm{dt}\right) \\ & = \\ & \text { luas petak }(\mathrm{ha})\end{aligned}$

Data debit yang didapatkan dari kebutuhan air tanaman kemudian akan dijadikan acuan untuk menentukan dimensi bukaan pintu air dengan menggunakan Persamaan (5) (Bos, 1989). Penentuan koefisien debit (Cd) dapat menggunakan persamaan yang telah dikembangkan oleh (Yen et al., 2001) dan (Lin et al., 2002) dalam Persamaan (6). Nilai parameter $\eta$ dihitung menggunakan Persamaan (7).

$Q=C_{d} \times B \times w \sqrt{2 \times g \times y_{1}}$

$C_{d}=\frac{C_{c}}{\sqrt{1+\eta}}$

$\eta=\frac{C_{c} \times w}{y_{1}}$

Keterangan:

B = lebar bukaan $(\mathrm{m})$

$\mathrm{W} \quad=$ tinggi bukaan $(\mathrm{m})$

$\mathrm{Q}=\operatorname{debit}\left(\mathrm{m}^{3} / \mathrm{det}\right)$

$\mathrm{C}_{\mathrm{d}} \quad=$ koefisien debit

$\mathrm{g}=$ percepatan grafitasi $\left(9,81 \mathrm{~m} / \mathrm{s}^{2}\right)$

$\mathrm{y}_{1}=$ tinggi muka air pintu hulu (m)

$\mathrm{Cc}=$ koefisien kontraksi

Ketinggian aliran dipilih beradasarkan rasio $\mathrm{y} 1 / \mathrm{w}$ dengan menggunakan kurva batasan tail-water level pada Gambar 2. 


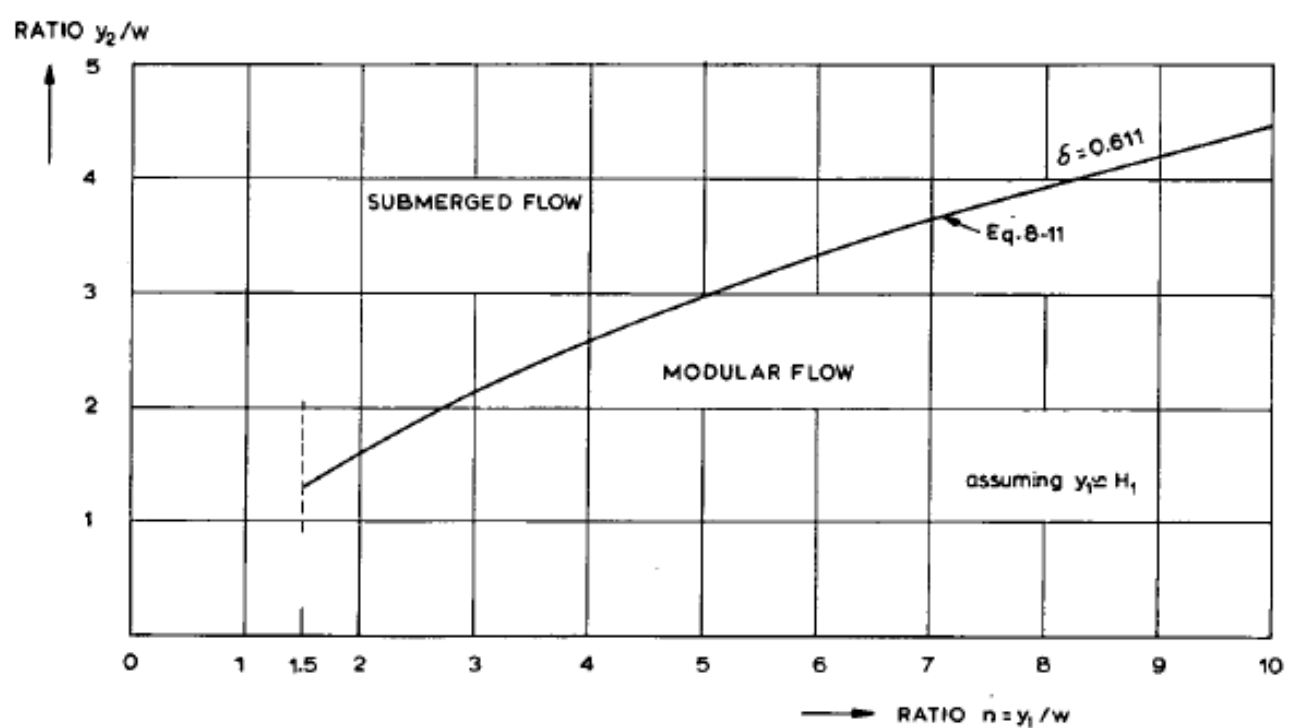

Gambar 2 Batasan Tail-Water Level untuk Aliran Modular di Bawah Pintu Air (Bos, 2019)

Setelah dimensi bukaan pintu air didapatkan, dimensi pintu air akan diperoleh berdasarkan jenis pintu air sorong yang dipilih sesuai standar yang berlaku. Data dimensi pintu air yang diperoleh menjadi acuan dalam pembuatan rencana anggaran biaya sesuai jenis pintu air yang digunakan.

\section{HASIL DAN PEMBAHASAN}

\section{Data Kebutuhan Air Tanaman}

Kebutuhan air untuk tanaman adalah kebutuhan air untuk memenuhi evapotranspirasi atau consumptive use tanaman, yaitu air irigasi yang diperlukan untuk memenuhi evapotranspirasi dikurangi curah hujan efektif (Linsey \& Franzini, 1979). Kebutuhan air tanaman penting untuk diketahui agar air irigasi dapat diberikan sesuai dengan kebutuhan. Dalam perancangan sistem irigasi, kebutuhan air untuk tanaman dihitung dengan menggunakan metode prakira empiris berdasar rumus tertentu (Purba, 2020). Data kebutuhan air tanaman yang digunakan merupakan data sekunder yang didapat dalam studi kasus Mangkung, Rambitan, NTB pada lahan seluas 50 ha untuk tanaman padi varietas lokal yang tercantum dalam KP-01 Dirjen Sumberdaya Air (KemenPU, 2010). Data yang digunakan dapat dilihat pada Tabel 1 . 
JSIL | Sanyota dan Setiawan : Desain Pintu Air Berbantu Kamputer untuk Saluran Irigasi Tersier

Tabel 1 Data Sekunder Kebutuhan Air Tanaman Padi Varietas Lokal

\begin{tabular}{|c|c|c|c|c|c|c|c|c|c|}
\hline \multirow{3}{*}{ Kegiatan Tanam } & \multirow{3}{*}{ Satuan } & \multicolumn{2}{|c|}{ Mar } & \multicolumn{2}{|c|}{ Apr } & \multicolumn{2}{|c|}{ Mei } & \multicolumn{2}{|c|}{ Jun } \\
\hline & & I & II & I & II & I & II & I & II \\
\hline & & 16 & 15 & 15 & 15 & 15 & 16 & 15 & 15 \\
\hline $\mathrm{ET}_{0}$ & $\mathrm{~mm} / \mathrm{hari}$ & 3.713 & 4.64 & 3.5 & 4.35 & 3.281 & 3.659 & 3.02 & 3.05 \\
\hline $\mathrm{Kc}$ & $\mathrm{mm} / \mathrm{hari}$ & & 1.1 & 1.1 & 1.1 & 1.1 & 1.1 & 1.05 & 0.95 \\
\hline PERC & $\mathrm{mm} / \mathrm{hari}$ & 2 & 2 & 2 & 2 & 2 & 2 & 2 & 2 \\
\hline SAT & $\mathrm{mm} / \mathrm{hari}$ & 11.7 & 12.3 & & & & & & \\
\hline WL & $\mathrm{mm} / \mathrm{hari}$ & & & & 3.333 & & 3.333 & & \\
\hline Hujan Efektif & $\mathrm{mm} / \mathrm{hari}$ & 3.148 & 6.425 & 7.32 & 1.974 & 0 & 0.003 & 3.47 & 0.008 \\
\hline
\end{tabular}

Debit Kebutuhan Air Tanaman

Hasil perhitungan data pada studi kasus Mangkung, Rambitan, NTB yang dilakukan menggunakan bantuan komputerisasi di spreadsheet Ms Excel kemudian dirangkum secara ringkas dalam Tabel 2.

Tabel 2 Hasil Perhitungan Debit Kebutuhan Air Tanaman Padi

\begin{tabular}{lrrrccccc}
\hline \multirow{2}{*}{ Uraian } & \multicolumn{2}{c}{ Mar } & \multicolumn{2}{c}{ Apr } & \multicolumn{2}{c}{ Mei } & \multicolumn{3}{c}{ Jun } \\
\cline { 2 - 10 } & \multicolumn{1}{c}{ I } & \multicolumn{1}{c}{ II } & \multicolumn{1}{c}{ I } & II & I & II & I & II \\
\cline { 2 - 10 } & \multicolumn{1}{c}{15} & \multicolumn{1}{c}{15} & 15 & 15 & 16 & 15 & 15 \\
\hline ETc (mm/hari) & 0.00 & 5.10 & 3.85 & 4.79 & 3.61 & 4.02 & 3.17 & 2.90 \\
IN (mm/hari) & 10.55 & 12.98 & -1.47 & 8.14 & 5.61 & 9.35 & 1.70 & 4.89 \\
Q (m 3 /dt $)$ & 0.09 & 0.12 & 0.00 & 0.07 & 0.05 & 0.08 & 0.02 & 0.04 \\
\hline
\end{tabular}

Debit kebutuhan air terbesar terjadi pada bulan Maret minggu kedua yaitu sebesar $0.12 \mathrm{~m}^{3} / \mathrm{dt}$ sementara pada bulan April minggu pertama tidak dibutuhkan adanya pengairan untuk tanaman dikarenakan kondisi hujan yang terjadi sudah cukup untuk memenuhi kebutuhan air tanaman.

\section{Dimensi Bukaan dan Dimensi Pintu Air}

Debit yang didapatkan dari hasil perhitungan kebutuhan air tanaman dijadikan data debit acuan untuk menentukan dimensi bukaan pintu air sesuai dengan jenis pintu air sorong yang dipilih. Terdapat dua jenis pintu air sorong yang dijadikan pilihan dalam perancangan pintu air pada spreadsheet yaitu pintu air sorong baja dan pintu air sorong glass fiber reinforce plastic (GFRP). Perncangan ini memutuhkan beberapa kondisi tambahan yang diasumsikan diantaranya kedalaman saluran pada perhitungan diasumsikan sedalam $1 \mathrm{~m}$ dan rasio y1/w yang dipakai sebesar 1.5 dengan asumsi ketinggian air hulu yang terjadi merupakan ketinggian air minimum dari debit. Hasil perhitungan dimensi bukaan pintu air sorong baja dapat dilihat pada Tabel 3 dan pintu sorong GFRP pada Tabel 4. 
Tabel 3 Hasil Perhitungan Dimensi Bukaan Pintu Air Sorong Baja

\begin{tabular}{|c|c|c|c|c|c|c|c|}
\hline \multicolumn{2}{|c|}{ Uraian } & $\begin{array}{c}\mathrm{Q} \\
\left(\mathrm{m}^{3} / \mathrm{det}\right)\end{array}$ & $\mathrm{y} 1 / \mathrm{w}$ & $\begin{array}{l}\mathrm{W} \\
(\mathrm{m})\end{array}$ & $\begin{array}{c}\mathrm{B} \\
(\mathrm{m})\end{array}$ & Jenis Pintu & Standar Pintu Air \\
\hline \multirow{2}{*}{ Mar } & $\mathrm{I}$ & 0.09 & 1.50 & 0.25 & 0.40 & Pintu Sorong Baja & Lebar $0.4 \mathrm{~s} / \mathrm{d} 0.6 \mathrm{~m}$; Tinggi $<0.8 \mathrm{~m}$ \\
\hline & II & 0.12 & 1.50 & 0.29 & 0.40 & Pintu Sorong Baja & Lebar $0.4 \mathrm{~s} / \mathrm{d} 0.6 \mathrm{~m}$; Tinggi $<0.8 \mathrm{~m}$ \\
\hline \multirow{2}{*}{ Apr } & I & 0.00 & 1.50 & 0.00 & 0.40 & Pintu Sorong Baja & Lebar $0.4 \mathrm{~s} / \mathrm{d} 0.6 \mathrm{~m}$; Tinggi $<0.8 \mathrm{~m}$ \\
\hline & II & 0.07 & 1.50 & 0.21 & 0.40 & Pintu Sorong Baja & Lebar $0.4 \mathrm{~s} / \mathrm{d} 0.6 \mathrm{~m} ;$ Tinggi $<0.8 \mathrm{~m}$ \\
\hline \multirow{2}{*}{ Mei } & $\mathrm{I}$ & 0.05 & 1.50 & 0.17 & 0.40 & Pintu Sorong Baja & Lebar $0.4 \mathrm{~s} / \mathrm{d} 0.6 \mathrm{~m}$; Tinggi $<0.8 \mathrm{~m}$ \\
\hline & II & 0.08 & 1.50 & 0.23 & 0.40 & Pintu Sorong Baja & Lebar $0.4 \mathrm{~s} / \mathrm{d} 0.6 \mathrm{~m}$; Tinggi $<0.8 \mathrm{~m}$ \\
\hline \multirow{2}{*}{ Jun } & I & 0.02 & 1.50 & 0.07 & 0.40 & Pintu Sorong Baja & Lebar $0.4 \mathrm{~s} / \mathrm{d} 0.6 \mathrm{~m}$; Tinggi $<0.8 \mathrm{~m}$ \\
\hline & II & 0.04 & 1.50 & 0.15 & 0.40 & Pintu Sorong Baja & Lebar $0.4 \mathrm{~s} / \mathrm{d} 0.6 \mathrm{~m} ;$ Tinggi $<0.8 \mathrm{~m}$ \\
\hline
\end{tabular}

Tabel 4 Hasil Perhitungan Dimensi Bukaan Pintu Air Sorong GFRP

\begin{tabular}{lccccccl}
\hline \multirow{2}{*}{ Uraian } & $\begin{array}{c}\text { Q } \\
\left(\mathrm{m}^{3} / \mathrm{det}\right)\end{array}$ & $\mathrm{y} 1 / \mathrm{w}$ & $\begin{array}{c}\mathrm{w} \\
(\mathrm{m})\end{array}$ & $\begin{array}{c}\mathrm{B} \\
(\mathrm{m})\end{array}$ & Jenis Pintu & Standar Pintu Air \\
\hline \multirow{2}{*}{ Mar } & I & 0.09 & 1.50 & 0.21 & 0.40 & Pintu Sorong GFRP & PU.FIGASI.01.500 \\
& II & 0.12 & 1.50 & 0.24 & 0.40 & Pintu Sorong GFRP & PU.FIGASI.01.500 \\
& I & 0.00 & 1.50 & 0.00 & 0.40 & Pintu Sorong GFRP & PU.FIGASI.01.500 \\
Apr & II & 0.07 & 1.50 & 0.18 & 0.40 & Pintu Sorong GFRP & PU.FIGASI.01.500 \\
& I & 0.05 & 1.50 & 0.14 & 0.40 & Pintu Sorong GFRP & PU.FIGASI.01.500 \\
\multirow{2}{*}{ Mei } & II & 0.08 & 1.50 & 0.19 & 0.40 & Pintu Sorong GFRP & PU.FIGASI.01.500 \\
& I & 0.02 & 1.50 & 0.06 & 0.40 & Pintu Sorong GFRP & PU.FIGASI.01.500 \\
& II & 0.04 & 1.50 & 0.11 & 0.40 & Pintu Sorong GFRP & PU.FIGASI.01.500
\end{tabular}

Lebar bukaan pintu air (B) untuk jenis pintu air sorong baja sebesar $0.4 \mathrm{~m}$ dan berdasarkan standar pintu air didapatkan dimensi untuk pintu air sorong baja yaitu lebar daun pintu air 0.4 $\mathrm{m}$, lebar pintu air $0.52 \mathrm{~m}$, tinggi daun pintu air $0.8 \mathrm{~m}$, rangka pintu dengan tinggi $150 \mathrm{~cm}$, lebar rangka $6 \mathrm{~cm}$, tebal rangka $0,6 \mathrm{~cm}$. Sementara untuk jenis

\section{Analisis Rencana Anggaran Biaya (RAB) Pintu Air}

Hasil dimensi yang diperoleh dan telah dibuat dalam gambar teknik menjadi data acuan dalam menyusun pintu air sorong GFRP dengan lebar 0.5 $\mathrm{m}$ dan berdasarkan standar pintu air didapatkan dimensi pintu air sorong GFRP yaitu lebar daun pintu air $0.5 \mathrm{~m}$, lebar pintu air $0.62 \mathrm{~m}$, tinggi daun pintu air $0.75 \mathrm{~m}$, rangka pintu dengan tinggi $150 \mathrm{~cm}$, lebar rangka $6 \mathrm{~cm}$, tebal rangka $0,6 \mathrm{~cm}$.

rencana anggaran biaya (RAB) pintu air. Hasil perhitungan RAB untuk pembuatan satu pintu air sorong baja dan satu pintu air sorong GFRP dirangkum secara ringkas dalam Tabel 5 dan Tabel 6. 
JSIL | Sanyota dan Setiawan : Desain Pintu Air Berbantu Kamputer untuk Saluran Irigasi Tersier

Tabel 5 Rencana Anggaran Biaya Pintu Sorong Baja

\begin{tabular}{|c|c|c|c|c|c|}
\hline No. & Uraian & Satuan & Volume & Harga Satuan & Total \\
\hline I & Kerangka Pintu & & & & \\
\hline I. 1 & Besi $60 \times 60 \times 0,6$ & $\mathrm{~kg}$ & 64.80 & Rp20,000 & Rp1,296,000 \\
\hline $\mathrm{I} .2$ & Angkur & buah & 10.00 & Rp12,000 & Rp120,000 \\
\hline II & Daun Pintu & buah & 1.00 & $\mathrm{Rp} 3,00,000$ & Rp3,000,000 \\
\hline III & Besi As Drat & $\mathrm{m}$ & 1.00 & Rp981,000 & Rp981,000 \\
\hline IV & Dudukan & buah & 1.00 & Rp500,000 & Rp500,000 \\
\hline V & Stir Kemudi & buah & 1.00 & Rp1,000,000 & Rp1,000,000 \\
\hline VI & Pekerjaan Perakitan & hari & 1.00 & Rp150,000 & Rp150,000 \\
\hline
\end{tabular}

Tabel 6 Rencana Anggaran Biaya Pintu Sorong GFRP

\begin{tabular}{rlcrrr}
\hline \multicolumn{1}{l}{ No. } & Uraian & Satuan & Volume & Harga Satuan & \multicolumn{1}{c}{ Total } \\
\hline I & Kerangka Pintu & & & & \\
I.1 & \multicolumn{1}{c}{ Besi 60x60x0,6 } & $\mathrm{kg}$ & 64.80 & $\mathrm{Rp} 20,000$ & $\mathrm{Rp} 1,296,000$ \\
I.2 & \multicolumn{1}{c}{ Angkur } & buah & 10.00 & $\mathrm{Rp} 12,000$ & $\mathrm{Rp} 120,000$ \\
II & Daun Pintu & & & & \\
II.1 & Komposisi Polymer & $\mathrm{kg}$ & 2.03 & $\mathrm{Rp} 69,000$ & $\mathrm{Rp} 140,346$ \\
II.2 & Chopped Stand Mat & $\mathrm{kg}$ & 0.26 & $\mathrm{Rp} 40,000$ & $\mathrm{Rp} 10,440$ \\
II.3 & Woven Roving & $\mathrm{kg}$ & 0.78 & $\mathrm{Rp} 45,000$ & $\mathrm{Rp} 35,280$ \\
II.4 & Mirror Glaze & $\mathrm{kg}$ & 0.13 & $\mathrm{Rp} 180,000$ & $\mathrm{Rp} 22,500$ \\
II.5 & PPA & $\mathrm{kg}$ & 0.13 & $\mathrm{Rp} 80,000$ & $\mathrm{Rp} 10,000$ \\
III & Pekerjaan Perakitan & $\mathrm{hari}$ & 2.00 & $\mathrm{Rp} 230,000$ & $\mathrm{Rp} 460,000$ \\
\hline & Total Biaya & & & & $\mathrm{Rp} 2,094,566$ \\
\hline
\end{tabular}

Pembuatan satu pintu air sorong baja dengan lebar pintu $0.4 \mathrm{~m}$ diestimasikan membutuhkan biaya sebesar Rp 7,547,000 sementara untuk satu pintu air sorong GFRP dengan lebar pintu $0.5 \mathrm{~m}$ membutuhkan biaya sebesar Rp 2,094,566.

\section{KESIMPULAN}

1. Evapotranspirasi tanaman sebesar $5.10 \mathrm{~mm} /$ hari dengan curah hujan efektif $6.43 \mathrm{~mm} /$ hari menghasilkan debit kebutuhan air tanaman sebesar $0.12 \mathrm{~m}^{3} / \mathrm{dt}$, sementara pada evapotranspirasi tanaman sebesar $3.17 \mathrm{~mm} /$ hari dengan curah hujan efektif $3.47 \mathrm{~mm} /$ hari menghasilkan debit kebutuhan air tanaman sebesar $0.02 \mathrm{~m}^{3} / \mathrm{dt}$.

2. Penggunaan pintu air dengan bukaan yang sesuai dapat memenuhi kebutuhan air tanaman tanpa berlebih sehingga pemanfaatan sumberdaya air menjadi lebih optimum. Seperti pada debit terbesar yaitu $0.12 \mathrm{~m}^{3} / \mathrm{dt}$ membutuhkan 
bukaan sebesar $0.29 \mathrm{~m}$ sementara debit terkecil yaitu $0.02 \mathrm{~m}^{3} / \mathrm{dt}$ membutuhkan bukaan sebesar 0.07 $\mathrm{m}$ pada pintu sorong baja.

3. Semakin besar debit yang dimasukkan maka semakin besar pula bukaan pintu air yang terjadi.

4. Perancangan berbantu komputer dapat menghasilkan dimensi pintu air sesuai kebutuhan dengan memasukkan data yang diperlukan.

5. Estimasi biaya untuk membuat satu pintu air sorong baja dengan lebar pintu 0.4 m sebesar Rp 7,047,000, sementara estimasi biaya untuk satu pintu air sorong GFRP dengan lebar pintu $0.5 \mathrm{~m}$ sebesar $\mathrm{Rp}$ $2,094,566$.

\section{DAFTAR PUSTAKA}

Rizal F, Alfiansyah, Rizalihadi M. Analisis perbandingan kebutuhan air irigasi tanaman padi metode konvensional dengan metode SRI organik. Jurnal Teknik Sipil. 2014; 3(4): 67-76.

Laumal FE, Hattu EP, Nope KN. Pengembangan pintu air irigasi pintar berbasis arduino untuk Daerah Irigasi Manikin. Jurnal Rekayasa Elektrika. 2017; 13(3): 139-144.

Rif'ah MI, Wibisono MA. Pengembangan computer aided design (CAD) warna batik. Forum Teknik. 2016; 37(1): 41-48.

Ningsih DH. Computer aided design / computer aided manufactur [CAD/CAM]. Jurnal Teknologi Informasi DINAMIK. 2005; 10(3): 143-149.

[KemenPU] Kementrian Pekerjaan Umum. Kriteria Perencanaan Bagian Petak Tersier: KP-05. Jakarta(ID): Direktorat Irigasi dan Rawa, Direktorat Jenderal Sumber
Daya Air, Kementerian Pekerjaan Umum; 2013.

Bos MG. Discharge measurement structures (Third Revision). Wageningen(NL): International Institute for Land Reclamation and Improvement/ILRI; 1989.

Yen JF, Lin CH, Tsai CT. Hydraulic characteristics and discharge control of sluice gates. Journal of the Chinese Institute of Engineers. 2001; 24(3): 301-310.

Lin $\mathrm{CH}$, Yen JF, Tsai CT. Influence of sluice gate contraction coefficient on distinguishing condition. Journal of Irrigation and Drainage Engineering. 2002; 128(4): 249-252.

Linsey RK, Franzini JB. Water Resources Engineering. New York(US): Mc Graw Hill Book Co; 1979.

Purba JH. Kebutuhan dan cara pemberian air irigasi untuk tanaman padi sawah (Oryza sativa L.). Jurnal Sains dan Teknologi. 2011; 10: 145-155.

[KemenPU] Kementrian Pekerjaan Umum. Kriteria Perencanaan Jaringan lrigasi Bagian Jaringan Irigasi: KP-01 (Revisi 2010). Jakarta(ID): Direktorat Irigasi, Direktorat Jenderal Sumber Daya Air, Kementerian Pekerjaan Umum; 2010. 
JSIL | Sanyota dan Setiawan : Desain Pintu Air Berbantu Kamputer untuk Saluran Irigasi Tersier 